\title{
Merit of Ginseng in the Improvement of Insulin Resistance
}

\author{
Juei-Tang Cheng* \\ Department of Medical Research, Chi-Mei Medical Center and Institute of Medical Science, Chang Jung Christian University, \\ Tainan 71101, Taiwan
}

In the present review, the merit of ginseng in the improvement of insulin resistance has been introduced. Using the results in previous studies, we found that ginseng or ginsenoside Rh2 has the ability to reduce glucose-insulin index in rats with insulin resistance. Insulin resistance was induced by feeding of fructose-rich chow in rats. Insulin resistance was characterized by regular methods. Effectiveness of ginseng powder or extract Rh2 was identified in this animal model. Also, the application of ginseng for handling of diabetic disorders in China has been discussed. According to Chinese traditional medicine, ginseng is merit in the treatment of diabetic disorders named as Shiaw-Ker in Chinese. Therefore, it is no doubt that ginseng is helpful in the control of diabetic disorders either prevention or the treatment. Otherwise, the potential effect of ginseng on nervous functions shall be investigated in the future.

Keywords: Ginsenoside Rh2, Insulin resistance, Panax ginseng, Rats, Shiaw-Ker

\section{INTRODUCTION}

Insulin resistance, a metabolic disorder increased worldwide in recent, characterized by a diminished ability of insulin-sensitive tissues and a marked decrease of glucose metabolism in response to insulin, is associated with some common diseases including type 2 diabetes, hypertension, obesity, and coronary heart disease [1]. The use of pharmacological intervention in addition to lifestyle modifications with weight loss and moderate exercise is accepted as a positive factor in health, and these are viewed as particularly useful in the management of obesity and cardiovascular diseases as well as prevention of insulin resistance and type 2 diabetes mellitus [2]. Currently, there is an enormous increase in the application of herbs and other alternative medicines in the treatment of diabetic disorders.

Ginseng (the root of Panax ginseng, C. A. Meyer, family Araliaceae) is a valuable agricultural commodity grown for use in many traditional therapies in Asia for several millennia. One of the most widely used and studied ginseng is Panax ginseng, also called Asian or Korean red ginseng. In addition to the modulation of psychologic and immune functions, ginseng has been demonstrated to possess neurotrophic and neuroprotective properties, which may be useful in preventing various forms of neuron cell loss including the nigrostriatal degeneration in Parkinson's disease [3-5]. Actually, ginseng has been used to treat diabetes and used as a tonic, often taken for years without adverse effects or toxicity [6]. Results of animal studies support the claim that the ginseng and other ginseng species, including Panax quinquefolius or American ginseng, showed antihyperglycemic activity [7-9]. It has been documented that ginseng elevated mood, improved psychophysical performance, and reduced fasting blood glucose and body weight in non-insulin-dependent diabetic patients [10]. Also, the American ginseng has an ability to attenuate

(c) This is an Open Access article distributed under the terms of the Creative Commons Attribution Non-Commercial License (http:/creativecommons.org/licenses/by-nc/3.0/) which permits unrestricted non-commercial use, distribution, and reproduction in any medium, provided the original work is properly cited.

Received 16 Jul. 2010, Revised 26 Aug. 2010, Accepted 30 Aug. 2010

*Corresponding author

E-mail: jtcheng@mail.cjcu.edu.tw

Tel: +886-6-331-8516, Fax: +886-6-331-7532 
postprandial glycemia in healthy individuals [11]. Recently, we observed that oral administration of ginseng has the ability to improve insulin resistance in rats receiving fructose-rich chow as well as delay the development of insulin resistance in rats, showing that ginseng may be used as an adjuvant therapy for treating diabetic patients with insulin resistance [12]. The main active components of ginseng are ginsenosides, containing a series of derivatives of the triterpene dammarane being attached by some sugar moieties, has been showed a variety of beneficial effects, including anti-inflammatory, antioxidant, and anticancer effects [13]. However, whether ginsenosides are the active principle(s) of ginseng for the effect on insulin resistance has not been identified.

Actually, ginsenosides are distributed in many parts of the ginseng plant, including the root, leaf, and berry. Different parts of the plant contain distinct ginsenoside profiles, and these parts may have different pharmacological activities [13]. Ginsenoside Rh2, the ginsenoside with little content in ginseng root (about $0.001 \%$ ), was found to have a clear control of enzymes during the G1 phase which prohibited the cells from entering into S phase and die naturally [14]. It also can destroy the synthesis of DNA and RNA and reverse cancer cell to normal function. Therefore, ginsenoside $\mathrm{Rh} 2$ is used to treat the cancer [14]. Additionally, ginsenosides $\mathrm{Rh} 2$ can also exhibit antiallergic activity originating from cell membrane-stabilizing activity and anti-inflammatory activity by the inhibition of nitric oxide and prostaglandin $\mathrm{E}_{2}$ production [15]. In recent, ginsenoside $\mathrm{Rh} 2$ from ginseng is mentioned to raise insulin secretion in Wistar rat [16]. It seems that ginsenoside $\mathrm{Rh} 2$ is valued as the bioactive principle in the glucose homeostasis.

The intake of fructose is raised with an increased consumption of soft drinks and many beverages containing high fructose in recent [17]. Studies in rats have demonstrated that high intake of fructose produced a decline of insulin sensitivity in the liver and peripheral tissues [17]. Thus, fructose has been implicated as the useful tool to induce insulin resistance in animals $[12,18]$. Due to fructose is consumed in significant amounts in Western diets, then, we investigated whether ginseng or ginsenoside $\mathrm{Rh} 2$ is effective to improve the insulin resistance in rats induced by the diet containing $60 \%$ fructose.

\section{MERIT OF GINSENG IN THE IMPROVEMENT OF INSULIN RESISTANCE}

In Wistar rats received high fructose (60\%) chow, the hypoglycemic action of tolbutamide was significantly reduced and the insulin resistance was also characterized [18]. The plasma glucose lowering activity of tolbutamide was used as reference in rats. After 1-week feeding of high fructose chow, the plasma glucose lowering activity of tolbutamide $(10 \mathrm{mg} / \mathrm{kg})$ was markedly reduced in rats fed fructose-rich chow. Then, we treated these rats with ginseng powder via oral intake $(125 \mathrm{mg} /$ $\mathrm{kg}$, three times daily for three days). A marked improvement of insulin resistance was observed in these rats received ginseng powder [12]. Characterization of the improvement of insulin resistance was carried out using the established method named as glucose-insulin index $[19,20]$. We found that ginseng powder has the ability to reduce glucose-insulin index in a dose-dependent manner [12]. This is consistent to the previous reports [21,22]. Although the active principles of ginseng are still not identified, it was totally named as ginsenoside while the subtypes of Rb1, Rb2, Rc, Rd, Re, and Rg were documented as the major [23]. However, there is no doubt that ginseng has the ability to improve insulin resistance after the intake of $150 \mathrm{mg} / \mathrm{kg}$ both our result [12] and others [21].

Actually, ginseng has been widely used to treat diabetic disorders in Chinese traditional medicine (CTM) for a long time. According to the documents in CTM, diabetic disorders are similar to the disease named as Shiaw-Ker in Chinese [24]. Many herbal mixtures were applied to handle Shiaw-Ker syndrome and Bai-Fu-Tang is suggested as effective one in prescriptions of CTM [24]. Meaning, this prescription (Bai-Fu-Tang) was enhanced to relieve Shiaw-Ker syndrome after the addition of ginseng in clinic of CTM. In animal study, we observed that the plasma glucose lowering action of Bai-Fu-Tang can be markedly raised by ginseng. Therefore, merit of ginseng powder in handling of diabetic disorders is reliable.

\section{MERIT OF GINSENOSIDE RH2 IN THE IM- PROVEMENT OF INSULIN RESISTANCE}

As mentioned above, ginsenoside $\mathrm{Rh} 2$ from ginseng is mentioned to raise insulin secretion in Wistar rat [16]. Thus, ginsenoside $\mathrm{Rh} 2$ is valued as the bioactive principle in the glucose homeostasis. In our study, Rh2 has the ability to improve insulin resistance in a dose-dependent fashion [25]. The fasting plasma level of glucose was significantly higher in rats fed with 4 weeks fructoserich chow than that fed with standard chow for same period. A dose-dependent reduction of plasma glucose was obtained in fructose-rich chow-fed rats receiving an in- 
travenous injection of ginsenoside $\mathrm{Rh} 2$ from $0.1 \mathrm{mg} / \mathrm{kg}$ to $1 \mathrm{mg} / \mathrm{kg}$ [25]. We treated $\mathrm{Rh} 2$ through injection into animal is going to rule out the pharmacokinetic parameters. Following the 3 days of ginsenoside Rh2 treatment ( $1 \mathrm{mg} / \mathrm{kg}$ per intravenous injection, 3 injections per day), plasma glucose levels in rats with insulin resistance fell to the value significantly lower than the vehicle-treated counterparts [25].

Moreover, the plasma glucose concentration in rats fed fructose-rich chow for 4 weeks was markedly increased and the plasma glucose lowering activity of tolbutamide was markedly attenuated. However, the plasma glucose lowering activity of tolbutamide in rats fed standard chow for 4 weeks was still marked. In rats received injection of ginsenoside $\mathrm{Rh} 2(1 \mathrm{mg} / \mathrm{kg}$ per intravenous injection, 3 times daily) after 1 week feeding of fructoserich chow, the plasma glucose lowered by tolbutamide was less to reduce. Even at the end of treatment, tolbutamide could effectively decrease the plasma glucose in rats receiving fructose-rich chow combined treatment with ginsenoside $\mathrm{Rh} 2$, the plasma glucose lowering activity of tolbutamide remained significant. Also, the glucoseinsulin index in rats received fructose-rich chow was reduced by same 3 days treatment of ginsenoside Rh2 [25]. Improvement of insulin resistance by ginsenoside $\mathrm{Rh} 2$ has thus been identified.

A dose-dependent reduction in plasma glucose response to short-acting human insulin was obtained in streptozotocin-diabetic rats repeatedly receiving same treatment with ginsenoside $\mathrm{Rh} 2(1 \mathrm{mg} / \mathrm{kg}$ per treatment, 3 times daily) for 10 days; the plasma glucose lowering activity of short-acting human insulin was markedly raised. An increase of insulin sensitivity by ginsenoside $\mathrm{Rh} 2$ can thus be considered. Taken together, it seems possible that ginsenoside $\mathrm{Rh} 2$ has an ability to increase insulin sensitivity to result in the improvement of insulin resistance.

\section{NO EFFECT OF GINSENOSIDE RH2 ON THE BODY WEIGHT OF RATS RECEIVED FRUC- TOSE-RICH CHOW}

Four weeks after fructose feeding, the body weight of rats was significantly increased, as compared with the standard chow-fed group. Otherwise, the daily food intake and the daily water intake in rats fed with fructoserich chow for 4 weeks were markedly elevated than the standard chow-fed group. The body weight of rats received same treatment with ginsenoside $\mathrm{Rh} 2(1 \mathrm{mg} / \mathrm{kg}$ per intravenous injection, 3 times daily) accompanied with the fructose-rich chow feeding was increased as relative to the standard chow-fed rats, while the value was lower than that of rats only fed with fructose-rich chow for same period. Rat received intravenous injection of ginsenoside $\mathrm{Rh} 2(1 \mathrm{mg} / \mathrm{kg}$ perinjection, 3 times daily) combined with the fructose-rich chow feeding for full period could lower the daily intake of food and water, though which was still higher than standard chowfed rats. Thus, ginsenoside Rh2 seems not belonged to active principles for decrease of body weight and/or antiobesity action of ginseng powder.

\section{MOLECULAR MECHANISMS OF GINSEN- OSIDE RH2}

It is hard to identify the action mechanism(s) of ginseng powder at molecular and/or cellular levels because this herb contained many active principles [13]. Basically, the molecular mechanism(s) of ginsenoside $\mathrm{Rh} 2$ or other ginsenosides will be easier to obtain similar to general chemical compound. In recent, we observed that ginsenoside $\mathrm{Rh} 2$ has an ability to activate glucocorticoid receptor in adipose 3T3-L1 cell line [26]. This action seems helpful in the increase of adipogenesis and be merit in the improvement of insulin resistance indirectly. But, the role of this action in increase of insulin sensitivity by ginsenoside $\mathrm{Rh} 2$ seems unlikely. The possible action mechanism(s) of ginsenoside Rh2 can be speculated as three ways shown in Fig. 1; one is the effect on membrane to initiate signals that can influence insulin signals. The others are the subcellular actions of ginsenoside Rh2 (Fig. 1).

Actually, increase of insulin sensitivity by agent(s) can be produced by two ways: one is the direct effect on cell to enhance insulin signals and/or bindings and another one is the indirect action through endogenous substance [27] including opioids [28]. Because ginsenoside Rh2 did not modify the blood sugar in rats lacking insulin, direct effect on cell can be ruled out. Action mediated endogenous substance or receptor will be more suitable to explain the merit in improvement of insulin resistance by ginsenoside $\mathrm{Rh} 2$. We have indicated that opioid is involved in the action of ginsenoside Rh2 [29]. However, the mechanism for this shall be clarified in the future.

\section{OTHER ACTIONS OF GINSENG}

It has been established that multiple constituents and multiple actions of ginseng powder [13]. Popular application of ginseng is widely observed not only in Eastern area but also in Western country [6]. Increase of 


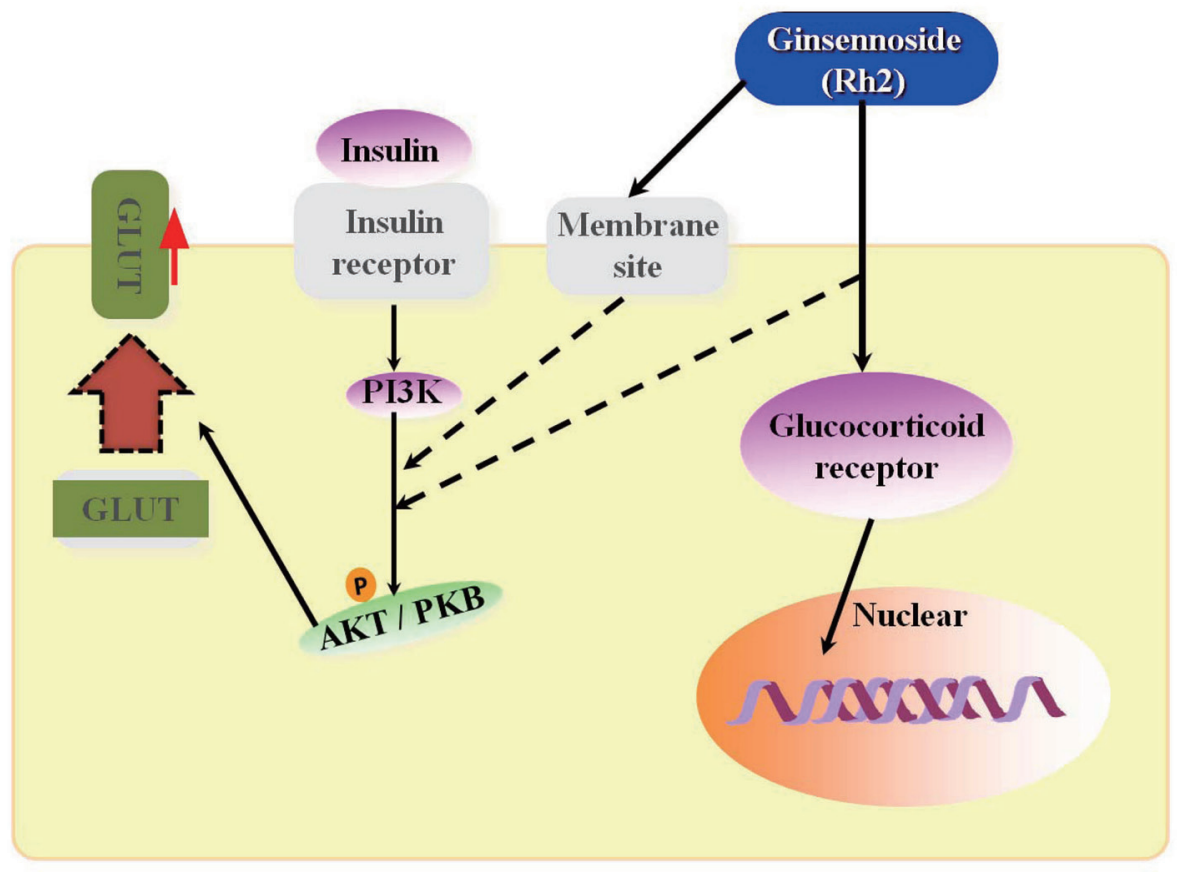

Fig. 1. Possible mechanisms for the improvement of insulin resistance by ginsenoside Rh2. Three possible ways can be considered; one is the effect on membrane, the others are the subcellular action including the activation of glucocorticoide receptor and the direct interaction with insulin signals. AKT/ PKB, protein kinase B; GLUT, glucose transporter; PI3K, phosphatidylinositol 3-kinase.

cholinergic tone by ginseng powder has been observed in animal [30]. It is not only responsible for insulin secretion in peripheral tissue but also related to the regulation of memory in brain [31]. Neuroprotective action of the ginseng extract G115 has been documented in two rodent models of Parkinson's disease [5]. We also found that ginsenoside $\mathrm{Rh} 2$ can against beta-amyloid-induced inhibition of rat brain astrocytes [32]. Effect of ginseng on nervous functions shall be investigated in advance.

\section{CONCLUSION}

According to the experience in Chinese society, ginseng is believed to have nutrient-like actions [24]. Basically, diabetic disorders named as Shiaw-Ker in Chinese are considered as the hypo-function of kidney route in CTM. Ginseng has been introduced to help the hypofunction of kidney route for a long time. Thus, according to the view of CTM, ginseng must be merit in the handling of Shiaw-Ker syndrome. Actually, we identified that ginseng or active principle Rh2 can improve the insulin resistance. Therefore, the effectiveness of ginseng has been characterized in scientific view.

\section{REFERENCES}

1. Kruszynska YT, Olefsky JM. Cellular and molecular mechanisms of non-insulin dependent diabetes mellitus. J Investig Med 1996;44:413-428.

2. Henriksen EJ. Invited review: effects of acute exercise and exercise training on insulin resistance. J Appl Physiol 2002;93:788-796.

3. Kennedy DO, Scholey AB. Ginseng: potential for the enhancement of cognitive performance and mood. Pharmacol Biochem Behav 2003;75:687-700.

4. Block KI, Mead MN. Immune system effects of echinacea, ginseng, and astragalus: a review. Integr Cancer Ther 2003;2:247-267.

5. Van Kampen J, Robertson H, Hagg T, Drobitch R. Neuroprotective actions of the ginseng extract G115 in two rodent models of Parkinson's disease. Exp Neurol 2003;184:521-529.

6. Kiefer D, Pantuso T. Panax ginseng. Am Fam Physician 2003;68:1539-1542.

7. Kimura M, Waki I, Tanaka O, Nagai Y, Shibata S. Pharmacological sequential trials for the fractionation of components with hypoglycemic activity in alloxan diabetic mice from ginseng radix. J Pharmacobiodyn 1981;4:402-409.

8. Kimura M, Suzuki J. The pattern of action of blended Chinese traditional medicines to glucose tolerance curves in genetically diabetic KK-CAy mice. J Pharmacobiodyn 1981;4:907-915.

9. Yokozawa T, Kobayashi T, Oura H, Kawashima Y. Studies on the mechanism of the hypoglycemic activity of 
ginsenoside-Rb2 in streptozotocin-diabetic rats. Chem Pharm Bull (Tokyo) 1985;33:869-872.

10. Kahn SE. Clinical review 135: the importance of betacell failure in the development and progression of type 2 diabetes. J Clin Endocrinol Metab 2001;86:4047-4058.

11. Kahn CR. Banting Lecture. Insulin action, diabetogenes, and the cause of type II diabetes. Diabetes 1994;43:10661084.

12. Liu TP, Liu IM, Cheng JT. Improvement of insulin resistance by panax ginseng in fructose-rich chow-fed rats. Horm Metab Res 2005;37:146-151.

13. Attele AS, Wu JA, Yuan CS. Ginseng pharmacology: multiple constituents and multiple actions. Biochem Pharmacol 1999;58:1685-1693.

14. Lee KY, Park JA, Chung E, Lee YH, Kim SI, Lee SK. Ginsenoside-Rh2 blocks the cell cycle of SK-HEP-1 cells at the G1/S boundary by selectively inducing the protein expression of p27kip1. Cancer Lett 1996;110:193-200.

15. Park EK, Choo MK, Kim EJ, Han MJ, Kim DH. Antiallergic activity of ginsenoside Rh2. Biol Pharm Bull 2003;26:1581-1584.

16. Lee WK, Kao ST, Liu IM, Cheng JT. Increase of insulin secretion by ginsenoside Rh2 to lower plasma glucose in Wistar rats. Clin Exp Pharmacol Physiol 2006;33:27-32.

17. Le KA, Tappy L. Metabolic effects of fructose. Curr Opin Clin Nutr Metab Care 2006;9:469-475.

18. Chang JC, Wu MC, Liu IM, Cheng JT. Increase of insulin sensitivity by stevioside in fructose-rich chow-fed rats. Horm Metab Res 2005;37:610-616.

19. Foianini KR, Steen MS, Kinnick TR, Schmit MB, Youngblood EB, Henriksen EJ. Effects of exercise training and ACE inhibition on insulin action in rat skeletal muscle. J Appl Physiol 2000;89:687-694.

20. Henriksen EJ, Jacob S, Kinnick TR, Teachey MK, Krekler M. Selective angiotensin II receptor receptor antagonism reduces insulin resistance in obese Zucker rats. Hypertension 2001;38:884-890.

21. Attele AS, Zhou YP, Xie JT, Wu JA, Zhang L, Dey L, Pugh W, Rue PA, Polonsky KS, Yuan CS. Antidiabetic effects of Panax ginseng berry extract and the identification of an effective component. Diabetes 2002;51:1851-1858.

22. Wang L, Higashiura K, Ura N, Miura T, Shimamoto K. Chinese medicine, Jiang-Tang-Ke-Li, improves insulin resis- tance by modulating muscle fiber composition and muscle tumor necrosis factor-alpha in fructose-fed rats. Hypertens Res 2003;26:527-532.

23. Xie JT, Mehendale SR, Wang A, Han AH, Wu JA, Osinski J, Yuan CS. American ginseng leaf: ginsenoside analysis and hypoglycemic activity. Pharmacol Res 2004;49:113117.

24. Cheng JT. Herbs used to treat diabetes mellitus in Chinese traditional medicine. In: Majumdar DK, Govil JN, Singh VK, editors. Recent progress in medicinal plants. Vol. 8, Phytochemistry \& pharmacology II. Houston: Sci Tech Publishing, 2003. p.175-184.

25. Lee WK, Kao ST, Liu IM, Cheng JT. Ginsenoside Rh2 is one of the active principles of Panax ginseng root to improve insulin sensitivity in fructose-rich chow-fed rats. Horm Metab Res 2007;39:347-354.

26. Niu CS, Yeh CH, Yeh MF, Cheng JT. Increase of adipogenesis by ginsenoside $(\mathrm{Rh} 2)$ in 3T3-L1 cell via an activation of glucocorticoid receptor. Horm Metab Res 2009; 41:271-276.

27. Park MY, Lee KS, Sung MK. Effects of dietary mulberry, Korean red ginseng, and banaba on glucose homeostasis in relation to PPAR-alpha, PPAR-gamma, and LPL RNA expressions. Life Sci 2005;77:3344-3354.

28. Su CF, Chang YY, Pai HH, Liu IM, Lo CY, Cheng JT. Infusion of beta-endorphin improves insulin resistance in fructose-fed rats. Horm Metab Res 2004;36:571-577.

29. Lai DM, Tu YK, Liu IM, Chen PF, Cheng JT. Mediation of beta-endorphin by ginsenoside $\mathrm{Rh} 2$ to lower plasma glucose in streptozotocin-induced diabetic rats. Planta Med 2006;72:9-13.

30. Lee KS, Yu WJ, Wang MJ, Wu HT, Chang CH, Cheng JT. Autonomic regulation of insulin secretion is changed by pentobarbital in mice. Neurosci Lett 2010;479:6-9.

31. Fisher A, Michaelson DM, Brandeis R, Haring R, Chapman S, Pittel Z. M1 muscarinic agonists as potential disease-modifying agents in Alzheimer's disease: rationale and perspectives. Ann N Y Acad Sci 2000;920:315-320.

32. Shieh PC, Tsao CW, Li JS, Wu HT, Wen YJ, Kou DH, Cheng JT. Role of pituitary adenylate cyclase-activating polypeptide (PACAP) in the action of ginsenoside Rh2 against beta-amyloid-induced inhibition of rat brain astrocytes. Neurosci Lett 2008;434:1-5. 